\title{
AN EMPIRICAL INVESTIGATION OF SIO NANO CONCENTRATION UNDER MQL ON SURFACE ROUGHNESS IN HARD MILLING OF JIS SKD61 STEEL
}

\section{The-Vinh Do}

Thai Nguyen University of Technology, Research Development Institute of Advanced Industrial Technology,

Thai Nguyen city, Vietnam

\section{Thanh-Dat Phan}

Thai Nguyen University of

Crossref

Technology, Faculty of Interna-

tional training,

Thai Nguyen city, Vietnam

Key words: surface roughness, hard milling, hardened SKD61 tool steel, $\mathrm{SiO}_{2}$ nanoparticles, MQL,

RSM

doi:10.5937/jaes18-27335

\section{Cite article:}

Do T. V., \& Phan, T. D. [2020]. An empirical investigation of $\mathrm{SIO}_{2}$ nano concentration under mql on surface roughness in hard milling of jis SKD61 steel. Journal of Applied Engineering Science, 18(3) 432 - 437. 


\title{
AN EMPIRICAL INVESTIGATION OF SIO NANO CONCENTRATION UNDER MQL ON SURFACE ROUGHNESS IN HARD MILLING OF JIS SKD61 STEEL
}

\author{
The-Vinh Do ${ }^{1 *}$, Thanh-Dat Phan ${ }^{2}$ \\ ${ }^{1}$ Thai Nguyen University of Technology, Research Development Institute of Advanced Industrial \\ Technology, Thai Nguyen city, Vietnam \\ ${ }^{2}$ Thai Nguyen University of Technology, Faculty of International training, Thai Nguyen city, Vietnam
}

Surface roughness is an important assessment of metal cutting. This paper presents an empirical investigation of cutting conditions on the surface roughness in hard milling SKD61 steel. The cutting speed, feed rate, depth of cut, and nanoparticle concentration were taken as the parameters in the experimental setup. The mixer of $\mathrm{SiO}_{2}$ particles with a size of 100nm based on cutting oil CT232 was used with 3 levels of concentration: 0, 2, and 4wt\%. Twenty-seven experiments were carried out based on the DOE method developed by G. Taguchi. The best model from response surface methodology (RSM) was developed regarding the surface roughness. Further analysis with ANOVA method was performed to confirm the significant of the achieved model as well as machining parameters. According to experiment results, the weight percent of nanoparticles concentration had a great impact on the surface roughness, only after the feed rate. Additionally, the excellent effectiveness in reducing the roughness of MQL nanofluid has been demonstrated when compared with conventional MQL.

Key words: surface roughness, hard milling, hardened SKD61 tool steel, SiO ${ }_{2}$ nanoparticles, MQL, RSM

\section{INTRODUCTION}

JIS SKD61 is the most representative hot-working tool steel which was used widely in molds and dies manufacturing. Because of its characteristics with high hardenability and toughness as well as great resistance for thermal cracking, it is recognized as difficult to cut material $[1,2]$. On the other hand, molds and dies require a smooth surface for the better quality of production [3]. Traditionally, grinding was used in finish machining after heat treatment to achieve the desired surface. However, recently manufacturers and researchers have focused on hard machining with a cutting tool as a replacement in order to reduce cost and process time. There have been many studies about optimizing the surface roughness in cutting hardened material and the results were satisfied $[4,5]$. As in [6] S Basak1, U S Dixit and J P Davim used radial basis function neural network in optimization of hard turning of AISI D2 steel with the hardness of 45 HRC. The optimum surface roughness value of less than $0.8 \mu \mathrm{m}$ could be found within a range of machining parameters. Another application of the Neural network with the helped of a Genetic algorithm (GA) was used in [7] to optimize the surface roughness while milling Inconel 718 steel with $415 \mathrm{HB}$. The optimum value of surface roughness found with GA was $0.32 \mu \mathrm{m}$.

Nevertheless, J. Paulo Davim [4] pointed out limitation and drawbacks of hard machining. Besides the high cost of the cutting tool and the demand for rigidity of a supportive system, the most concern is the heat generated in cutting which is the reason for thermal shock, more tool wear, shorter tool life, deterioration of workpiece surface, and so on. Therefore, in order to carry out hard machining, it is vital to find ways to ease the heat. In wet machining, lubricant floods onto the cutting area reducing the heat and protecting both cutting tools and workpiece. However, the issues related to human health and environment along with cost and waste have raised the alert among researchers and manufacturers[8]. In certain machining conditions, dry machining or high speed machining are preferred over wet machining.

A better way of machining hard materials is using machining assisted methods such as cryogenic machining, laser-assisted machining (LAM), minimum quantity lubrication (MQL). It can be considered a win-win as these methods help both reducing the negative effects of too much lubricant and raising the efficiency of the cutting system. Further than that, recently researchers have found excellent results by adding nanoparticles into $M Q L$. Different types of nanoparticles were used by researchers including $\mathrm{SiO}_{2}, \mathrm{Al}_{2} \mathrm{O}_{3}, \mathrm{MoS}_{2}, \mathrm{ZrO}_{2}, \mathrm{CNT}, \mathrm{SiC}$, $\mathrm{PCD}$, and graphite $[9,10]$ while others are under investigation. The effectiveness of nanoparticles has been reported in turning [11-13], milling [14, 15], drilling [16] for better surface quality, prolonged tool life, reducing cutting force, reducing tool wear, and reducing power \& energy consumption. Khaled Ali Osman et al. [17] performed slot milling of Ti6Al4V under various concentrations of hBN nanoparticles in order to optimize surface quality and cutting forces. With comprehensive research beforehand, they provide a clear classification of sustainable cutting fluid supply technologies. They concluded that the best surface roughness and least cutting force achieved with a $24.75 \%$ volume concentration. In [18], Ramanuj Kumar et al. investigated the effects of using $\mathrm{Al}_{2} \mathrm{O}_{3}$ \& $\mathrm{TiO}_{2}$ nanoparticles on hard turning AISI D2 
steel (55HRC). The result showed the most favorable achievement with only $0.01 \mathrm{wt} \%$ concentrations of $\mathrm{TiO}_{2}$ : $29 \%$ reduction of tool wear, $9.7 \%$ reduction of cutting temperature, and $14.3 \%$ reduction of surface roughness. In another research, while working with titanium alloy $\mathrm{Ti}_{6} \mathrm{Al}_{4} \mathrm{~V}$, Lan Dong et al. used six different nanoparticles including $\mathrm{Al}_{2} \mathrm{O}_{3}, \mathrm{MOS}_{2}, \mathrm{SiO}_{2}, \mathrm{CNTs}, \mathrm{SiC}$, and graphite. Their experiment results pointed out that $\mathrm{Al}_{2} \mathrm{O}_{3}$ and $\mathrm{SiO}_{2}$ nanoparticles are highly suitable regarding environmental protection as well as excellent surface roughness quality.

It is noticeable that most publications suggested further investigation with machining parameters to improve effectiveness while utilizing nanoparticles in the MQL technique. After a comprehensive review [19], Zafar Said et al. concluded that nanofluid with the MQL technique was one of the best methods for lubricant, yet encouraged future researches for optimum effects. In this work, cutting speed, feed rate, depth of cut, and nanoparticle concentration were used as parameters to optimize the milling process of SKD61 steel regarding the surface roughness under MQL.

\section{EXPERIMENT SETUP}

Table 1 shows a brief experimental setup. An SKD61

Table 1: Hard-milling process information

\begin{tabular}{|l|l|}
\hline Items & Description \\
\hline CNC Machine & Victor V-Center-4 \\
\hline $\begin{array}{l}\text { Surface roughness } \\
\text { measuring instrument }\end{array}$ & Sj-401 \\
\hline Cutting tool & Ф10 TiAIN \\
\hline Work-piece material & SKD61 50HRC \\
\hline Work-piece dimensions & 200mm x 100mm x 50mm \\
\hline MQL nozzle & Noga - MC 1700 \\
\hline
\end{tabular}

Table 2: Chemical compositions of the SKD61 steel (weight \%)

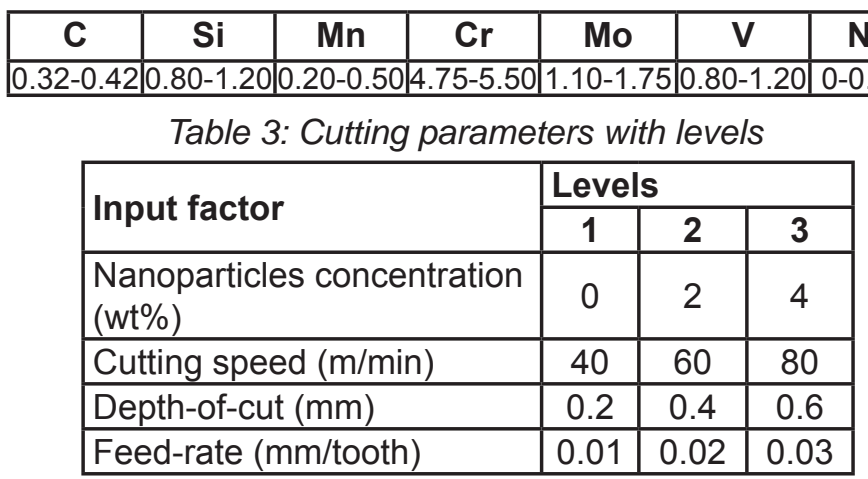

Table 4: Information about MQL condition

\begin{tabular}{|l|l|}
\hline Items & Description \\
\hline Fluid flow $(\mathrm{mL} / \mathrm{h})$ & 50 \\
\hline Pressure $\left(\mathrm{kg} / \mathrm{cm}^{2}\right)$ & 3 \\
\hline Based Lubricant & Cutting oil CT232 \\
\hline Nanoparticles & $\begin{array}{l}\mathrm{SiO}_{2} \text { particle with a } \\
\text { size of 100nm }\end{array}$ \\
\hline
\end{tabular}

steel work-piece was mounted onto the machining table of on a Victor V-Center-4 vertical machining center for every experiment. The material compositions of SKD61 are shown in Table 2. Each work-piece block has the dimensions of $200 \mathrm{~mm} \times 100 \mathrm{~mm} \times 50 \mathrm{~mm}$. The nanoparticle concentration (wt $\%)$, cutting speed $(\mathrm{m} / \mathrm{min})$, depth of cut $(\mathrm{mm})$, and feed-rate $(\mathrm{mm} / \mathrm{tooth})$ parameters are presented in Table 3. The cutting tool was $\Phi 10$ TiAIN coated end mill made by CMTec Company (Taiwan) with four flutes rake angle of $12^{\circ}$, and the helix angle of $35^{\circ}$. The description of the MQL condition shows in Table 4. Lubricant fluid based on cutting oil CT232 mixed with $100 \mathrm{~nm} \mathrm{SiO}_{2}$ particles was chosen to enhance the performance of MQL. The flow rate of the mixture was set to $50 \mathrm{ml} / \mathrm{h}$ and the pressure was $3 \mathrm{~kg} / \mathrm{cm}^{2}$. The concentration of nanoparticles in the fluid was $2 \mathrm{wt} \%$. A Noga-MC 1700 nozzle was used for MQL setup with an angle of $60^{\circ}$. Slot milling was performed in all runs. The surface roughness data was collected via Mitutoyo SJ-401 Surface Profilometer.

Each experiment was repeated three times to eliminate the experimental error.

\section{RESULT AND DISCUSSIONS}

The data collected throughout the experiments are presented in Table 5. The preset machining parameter including the nanoparticles concentration (c), the cutting speed (v), the depth of cut (d), and the feed rate (f) were

Table 5: The result of the experiment

\begin{tabular}{|c|c|c|c|c|c|c|c|c|}
\hline \multirow{2}{*}{ Run } & \multirow{c}{*}{$\mathbf{v}$} & \multirow{2}{*}{$\mathbf{d}$} & \multirow{2}{*}{$\mathbf{f}$} & \multicolumn{4}{|c|}{ Ra $(\boldsymbol{\mu m})$} \\
\cline { 6 - 9 } & & & & Trial 1 & Trial 2 & Trial 3 & Average \\
\hline $\mathbf{1}$ & 0 & 40 & 0.2 & 0.01 & 0.198 & 0.198 & 0.204 & 0.2 \\
\hline $\mathbf{2}$ & 0 & 40 & 0.4 & 0.02 & 0.245 & 0.248 & 0.251 & 0.248 \\
\hline $\mathbf{3}$ & 0 & 40 & 0.6 & 0.03 & 0.313 & 0.31 & 0.313 & 0.312 \\
\hline $\mathbf{4}$ & 0 & 60 & 0.2 & 0.02 & 0.226 & 0.226 & 0.22 & 0.224 \\
\hline $\mathbf{5}$ & 0 & 60 & 0.4 & 0.03 & 0.27 & 0.278 & 0.28 & 0.276 \\
\hline $\mathbf{6}$ & 0 & 60 & 0.6 & 0.01 & 0.181 & 0.183 & 0.179 & 0.181 \\
\hline $\mathbf{7}$ & 0 & 80 & 0.2 & 0.03 & 0.258 & 0.259 & 0.254 & 0.257 \\
\hline $\mathbf{8}$ & 0 & 80 & 0.4 & 0.01 & 0.166 & 0.169 & 0.166 & 0.167 \\
\hline $\mathbf{9}$ & 0 & 80 & 0.6 & 0.02 & 0.218 & 0.213 & 0.211 & 0.214 \\
\hline $\mathbf{1 0}$ & 2 & 40 & 0.2 & 0.02 & 0.184 & 0.18 & 0.173 & 0.179 \\
\hline $\mathbf{1 1}$ & 2 & 40 & 0.4 & 0.03 & 0.29 & 0.3 & 0.295 & 0.295 \\
\hline $\mathbf{1 2}$ & 2 & 40 & 0.6 & 0.01 & 0.176 & 0.181 & 0.171 & 0.176 \\
\hline $\mathbf{1 3}$ & 2 & 60 & 0.2 & 0.03 & 0.27 & 0.244 & 0.251 & 0.255 \\
\hline $\mathbf{1 4}$ & 2 & 60 & 0.4 & 0.01 & 0.233 & 0.231 & 0.22 & 0.228 \\
\hline $\mathbf{1 5}$ & 2 & 60 & 0.6 & 0.02 & 0.251 & 0.26 & 0.278 & 0.263 \\
\hline $\mathbf{1 6}$ & 2 & 80 & 0.2 & 0.01 & 0.122 & 0.129 & 0.133 & 0.128 \\
\hline $\mathbf{1 7}$ & 2 & 80 & 0.4 & 0.02 & 0.21 & 0.21 & 0.15 & 0.19 \\
\hline $\mathbf{1 8}$ & 2 & 80 & 0.6 & 0.03 & 0.272 & 0.272 & 0.272 & 0.272 \\
\hline $\mathbf{1 9}$ & 4 & 40 & 0.2 & 0.03 & 0.261 & 0.265 & 0.254 & 0.26 \\
\hline $\mathbf{2 0}$ & 4 & 40 & 0.4 & 0.01 & 0.133 & 0.137 & 0.144 & 0.138 \\
\hline $\mathbf{2 1}$ & 4 & 40 & 0.6 & 0.02 & 0.155 & 0.158 & 0.152 & 0.155 \\
\hline $\mathbf{2 2}$ & 4 & 60 & 0.2 & 0.01 & 0.096 & 0.097 & 0.101 & 0.098 \\
\hline $\mathbf{2 3}$ & 4 & 60 & 0.4 & 0.02 & 0.139 & 0.129 & 0.143 & 0.137 \\
\hline $\mathbf{2 4}$ & 4 & 60 & 0.6 & 0.03 & 0.211 & 0.213 & 0.206 & 0.21 \\
\hline $\mathbf{2 5}$ & 4 & 80 & 0.2 & 0.02 & 0.131 & 0.122 & 0.131 & 0.128 \\
\hline $\mathbf{2 6}$ & 4 & 80 & 0.4 & 0.03 & 0.205 & 0.204 & 0.191 & 0.2 \\
\hline $\mathbf{2 7}$ & 4 & 80 & 0.6 & 0.01 & 0.13 & 0.124 & 0.124 & 0.126 \\
\hline
\end{tabular}


selected by the L27 orthogonal array of Taguchi method with the 1, 2, 5, 9 columns respectively. Accordingly, 27 experiments were carried out to study the effect of these cutting conditions to the surface roughness $\mathrm{Ra}$. The trial runs showed the reliability of the machining system as the maximum difference Ra between trials was 0.06 .

The following model was built based on the Surface Response Methodology to predict and optimize the surface roughness $\mathrm{Ra}$ as shown in the following equation.

$R a=0.164+0.0049 c+0.00026 v+0.101 d+0.14 f-$ $-0.00613 c^{*} c-0.000014 v^{*} v-0.167 d^{*} d+168 f^{*} f+$ $+0.000071 c^{*} v-0.0022 c^{*} d-0.057 c^{*} f+$ $+0.00205 v^{*} d-0.0177 v^{*} f-1.81 d^{*} f$

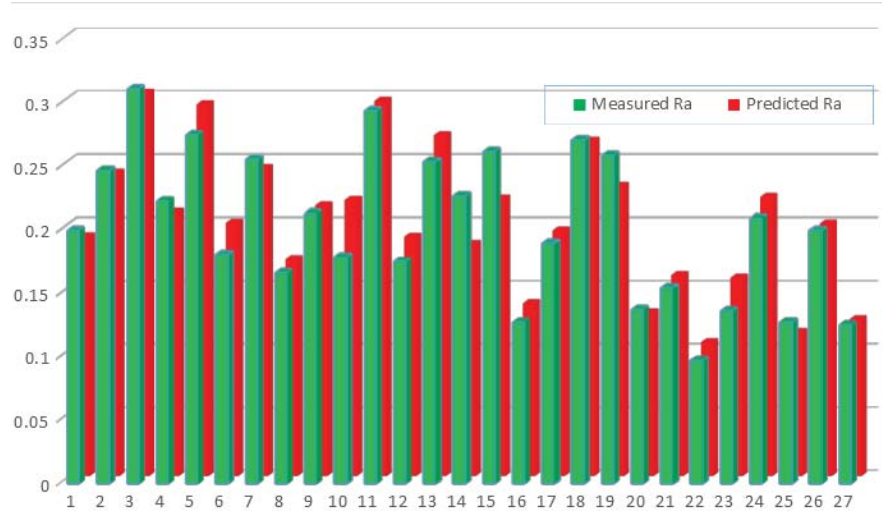

Figure 1: Comparison between measured and predicted surface roughness

A comparison of the predicted and the measured value of the surface roughness visualized in Figure 1 showed rather a similarity. As shown in the figure, the measured and predicted results have a fine correlation. Therefore, the mathematical models built are reliable.

Best Ra value achieved from the model is shown in Table 6 when an experiment with cutting speed of $80 \mathrm{~m} / \mathrm{min}$, feed rate of $0.01 \mathrm{~mm} /$ tooth, depth of cut of $0.2 \mathrm{~mm}$, and the nanoparticles concentration of $4 \%$. This verification test was carried out with these parameters to confirm the accuracy of the model. The predicted value calculated by (1) was $0.0841 \mu \mathrm{m}$ while the measured value of the verification test was $0.0940 \mu \mathrm{m}$. Even though the error in this one-time-measure was approximately $14 \%$, the machined surface with optimized parameters was the smallest compared to that of previous $27 \times 3$ experiments. The achieved $\mathrm{Ra}$ is considered an improvement compared to similar work on JIS SKD 61 in [20].

Further analysis of variance (ANOVA) was conduct in Minitab 17 software to analyze the influence of input parameters and the fitness of the model. The P-value column in Table 7 indicates the significant of each parameter of the milling process to the response (i.e., the surface roughness) of the model. As long as that value is less than 0.05, the corresponding parameter has statistical significant. Hence, the feed rate (f) clearly has the most effect with $50.3 \%$ contribution to the model, following by the nanoparticles concentration (c) with $24.69 \%$. The two other parameters including the speed of cut (v) and the depth of cut (d) have a rather small effect on the final result of the experiments. The total coefficient of determination R-sq of the model is $89.76 \%$. It means that the model has successfully predicted the value of Ra.

Table 6: The results of surface roughness optimization

\begin{tabular}{|c|c|c|c|c|c|c|c|c|}
\hline \multirow{2}{*}{ Response } & \multirow{2}{*}{ Goal } & \multicolumn{4}{|c|}{ Optimal values } & \multirow[t]{2}{*}{ Predicted } & \multirow[t]{2}{*}{ Measured } & \multirow[t]{2}{*}{ Error (\%) } \\
\hline & & $\mathrm{V}(\mathrm{m} / \mathrm{min})$ & $\mathrm{f}(\mathrm{mm} /$ tooth $)$ & $\mathrm{d}(\mathrm{mm})$ & c (wt $\%)$ & & & \\
\hline Roughness & Min. & 80 & 0.01 & 0.2 & 4 & 0.0821 & 0.0940 & $14 \%$ \\
\hline
\end{tabular}

Table 7: ANOVA value

\begin{tabular}{|c|c|c|c|c|c|c|}
\hline Source & DF & Ad-SS & Adj-MS & F-Value & P-Value & \%C \\
\hline Model & 14 & 0.079414 & 0.005672 & 7.51 & $\mathbf{0 . 0 0 1}$ & 89.76 \\
\hline Linear & 4 & 0.072529 & 0.018132 & 24.01 & $\mathbf{0 . 0 0 0}$ & 81.97 \\
\hline $\mathrm{c}$ & 1 & 0.021841 & 0.021841 & 28.91 & $\mathbf{0 . 0 0 0}$ & 24.69 \\
\hline $\mathrm{v}$ & 1 & 0.004387 & 0.004387 & 5.81 & $\mathbf{0 . 0 3 3}$ & 4.96 \\
\hline $\mathrm{d}$ & 1 & 0.001800 & 0.001800 & 2.38 & 0.149 & 2.03 \\
\hline $\mathrm{f}$ & 1 & 0.044501 & 0.044501 & 58.92 & $\mathbf{0 . 0 0 0}$ & 50.30 \\
\hline Square & 4 & 0.005750 & 0.001437 & 1.90 & 0.175 & 6.50 \\
\hline $\mathrm{c}^{*} \mathrm{c}$ & 1 & 0.003602 & 0.003602 & 4.77 & 0.050 & 4.07 \\
\hline $\mathrm{v}^{*} \mathrm{v}$ & 1 & 0.000181 & 0.000181 & 0.24 & 0.633 & 0.20 \\
\hline $\mathrm{d}^{*} \mathrm{~d}$ & 1 & 0.000267 & 0.000267 & 0.35 & 0.563 & 0.30 \\
\hline $\mathrm{f}^{*} \mathrm{f}$ & 1 & 0.001700 & 0.001700 & 2.25 & 0.159 & 1.92 \\
\hline 2-Way Interaction & 6 & 0.001135 & 0.000189 & 0.25 & 0.950 & 1.28 \\
\hline $\mathrm{c}^{*} \mathrm{v}$ & 1 & 0.000090 & 0.000090 & 0.12 & 0.736 & 0.10 \\
\hline $\mathrm{c}^{*} \mathrm{~d}$ & 1 & 0.000008 & 0.000008 & 0.01 & 0.918 & 0.01 \\
\hline $\mathrm{c}^{*} \mathrm{f}$ & 1 & 0.000014 & 0.000014 & 0.02 & 0.892 & 0.02 \\
\hline $\mathrm{v}^{*} \mathrm{~d}$ & 1 & 0.000756 & 0.000756 & 1.00 & 0.337 & 0.85 \\
\hline $\mathrm{v}^{*} \mathrm{f}$ & 1 & 0.000140 & 0.000140 & 0.19 & 0.674 & 0.16 \\
\hline $\mathrm{d}^{*} \mathrm{f}$ & 1 & 0.000148 & 0.000148 & 0.20 & 0.666 & 0.17 \\
\hline Error & 12 & 0.009064 & 0.000755 & - & - & - \\
\hline Total & 26 & 0.088478 & - & - & - & - \\
\hline
\end{tabular}


The plotting of the parameters' effect on the Ra can be seen in Figure 2 where the average value of Ra measured is used. Whereas, the optimized value of Ra via the RSM is shown in Figure 3. It is clear that the Ra value changes greatly when the value of concentration and feed rate coefficients change. The slopes indicated that the surface roughness decreases as the value of concentration increases to $4 \%$ or the value of feed rate decreases to 0.01 . As discussed in [21], the uncut chip would be thicker as an increasing feed rate, resulting in higher cutting forces and vibration. On the other hand, Mohd Asyraf Mahboob Ali et al. [11] pointed out that the increase of nanoparticle concentration strengthened the thin protective film on the machined surface so the surface could be improved. It was also discussed that the low friction behavior of nanoparticles contributed to minimizing the frictional effects on tool-workpiece, hence reducing tool wear and cutting force. Nevertheless, the feed rate had more influence on surface quality.

The interaction effect of nanoparticle (c) and feed rate (f), cutting speed (v), and depth of cut (d) over Ra is shown in Figure 4. The plots reveal which cutting parameter has more impact on the surface roughness when comparing with the nanoparticle concentration. It is clear that only the feed rate has more impact.

The interval plot in Figure 5 indicates the differential of the average value Ra within 27 experiments. It is notable that the surface roughness decreases significantly with increasing the concentration from 0 to $4 \mathrm{wt} \%$. The best roughness is obtained when a nanoparticle concentration of $4 \mathrm{wt} \%$ is applied. Figure 5 shows that the roughness
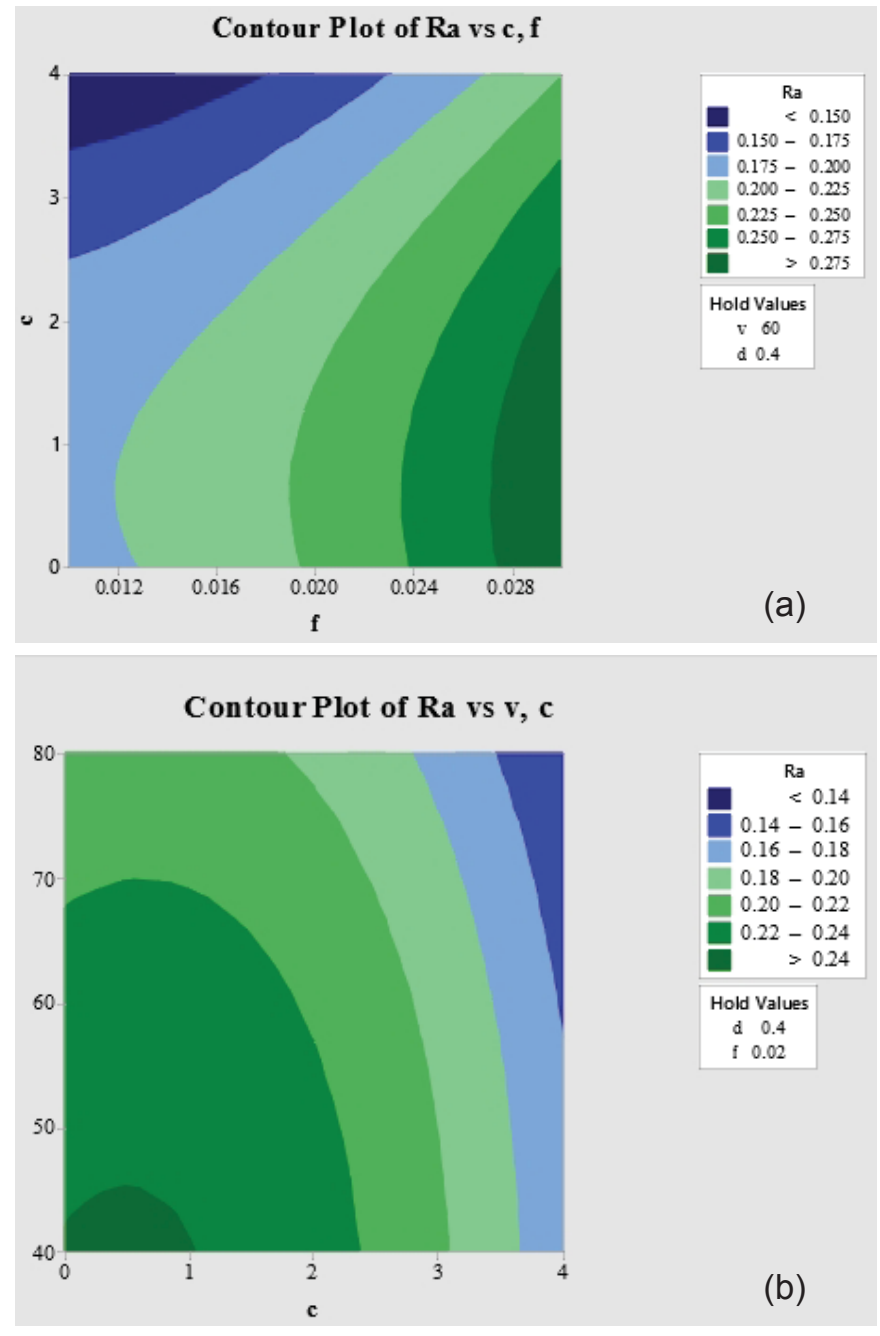

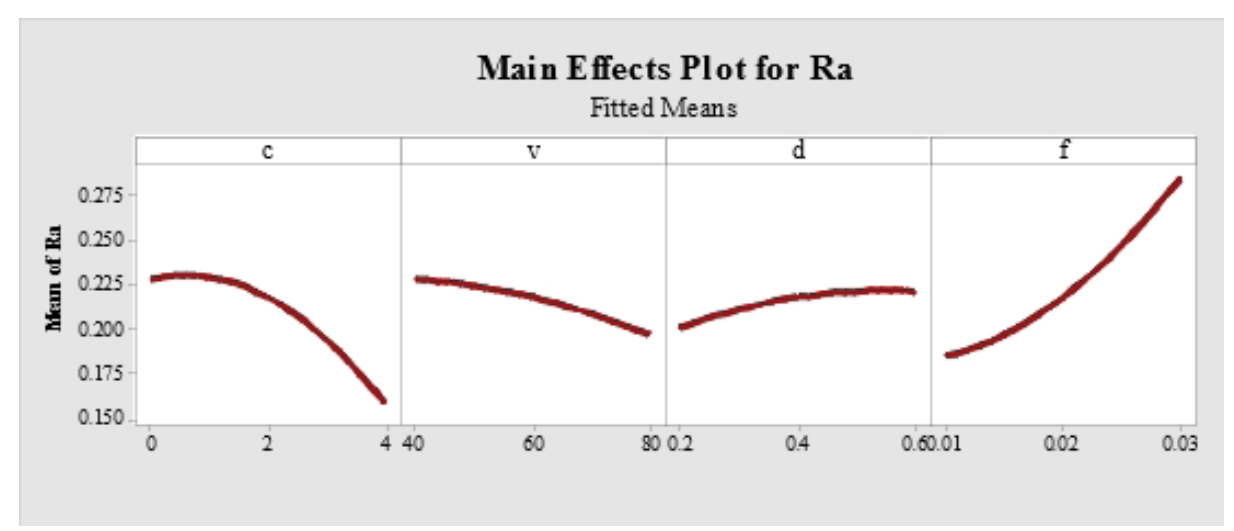

Figure 2: Interval Plot for roughness

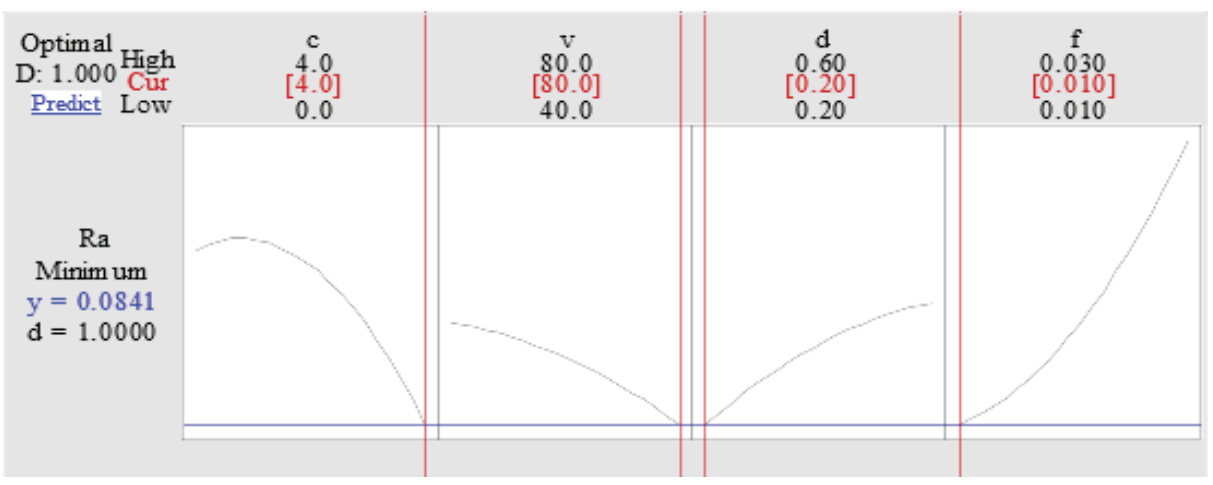

Figure 3: Optimization Ra plot 


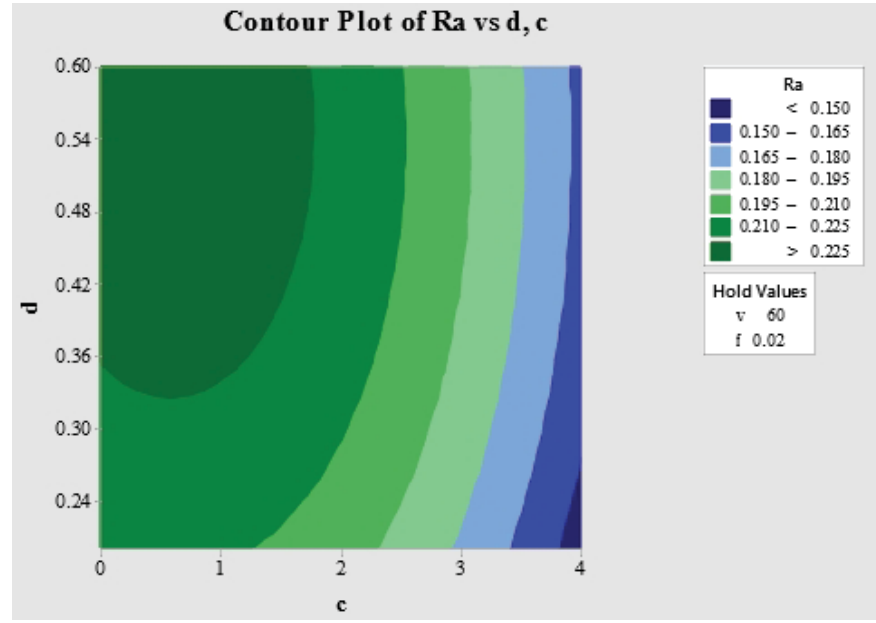

Figure 4: Interaction effect over Surface roughness of

(a) Nanoparticles concentration \& Feed rate

(b) Nanoparticles concentration \& Cutting speed

(c) Nanoparticles concentration \& Depth of cut

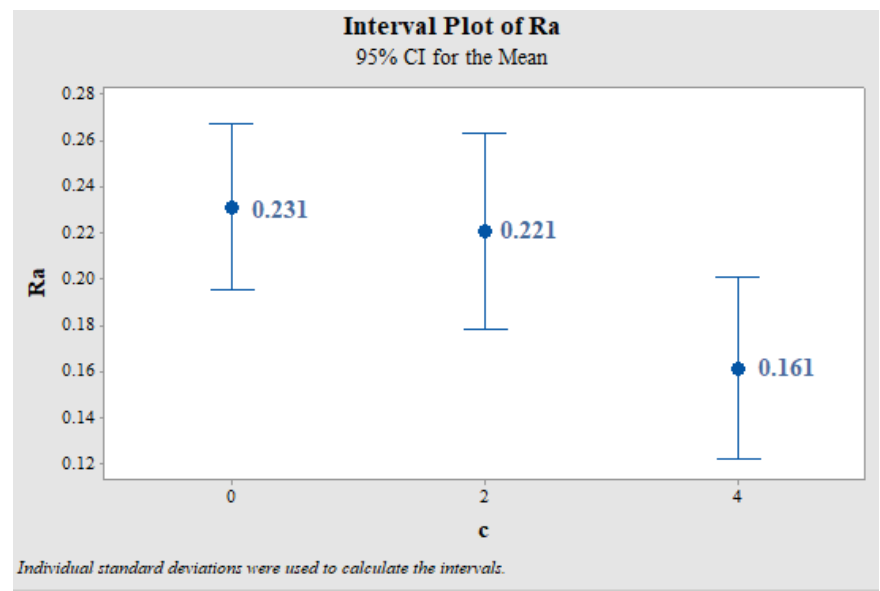

Figure 5: Interval plot of surface roughness

obtained with the optimum concentration (nanoparticle concentration of $4 \mathrm{wt} \%$ ) was reduced by $30.3 \%$ when compared to that when machining by conventional MQL (nanoparticle concentration of $0 \mathrm{wt} \%$ ). It can be asserted that the quality of machined surface achieved by nanofluid is better than conventional MQL. Due to nanofluid's advanced heat transfer and tribological properties, the cutting process is more convenient, the cutting tool maintains the initial hardness and cutting ability [22]. This leads to better roughness.

\section{CONCLUSION}

This research investigates the cutting condition including the cutting speed, feed rate, depth of cut, and $\mathrm{SiO}_{2}$ nanoparticle concentration to find the best machining parameters regarding surface roughness for milling SKD61 steel under the MQL technique. An empirical model based on RSM was built to find the optimum value of Ra. The best Ra value $0.094 \mu \mathrm{m}$ was achieved with cutting speed of $80 \mathrm{~m} / \mathrm{min}$, feed rate of $0.01 \mathrm{~mm} /$ tooth, depth of cut of $0.2 \mathrm{~mm}$, and the nanoparticles concentration of
$4 w t \%$. Feed rate and nanoparticle concentration had a significant impact on the machining result. In addition, the excellent effectiveness in reducing the roughness of nanofluid MQL has been demonstrated when compared with conventional MQL. The roughness obtained with the optimum nanoparticle concentration was reduced by $30.3 \%$ when compared to that when machining by conventional MQL.

\section{ACKNOWLEDGMENTS}

The authors wish to thank Thai Nguyen University of Technology. This work was supported by Thai Nguyen University of Technology.

\section{REFERENCE}

1. Kodama, H., Shindou, M., et al. (2012). An end-milling condition decision support system using data-mining for difficult-to-cut materials. Advanced Materials Research, 565, 472-477.DOI:10.4028/ www.scientific.net/AMR.565.472

2. Do, T.-V. and Hsu, Q.-C.(2016). Optimization of Minimum Quantity Lubricant Conditions and Cutting Parameters in Hard Milling of AISI H13 Steel. Applied Sciences, vol. 6,83. DOI:10.3390/app6030083.

3. Arruda, E.M., de Paiva, A.P., et al. (2019). Robust optimisation of surface roughness of AISI H13 hardened steel in the finishing milling using ball nose end mills. Precision Engineering, vol. 60,194-214. DOI:10.1016/j.precisioneng.2019.07.013.

4. Davim, J.P.(2011). Machining of hard materials. Springer Science \& Business Media. DOI:10.1007/978-1-84996-450-0

5. Jain, A. and Bajpai, V. (2020)Introduction to highspeed machining (HSM), in High Speed Machining, ed: Elsevier, pp. 1-25,DOI:10.1016/B978-0-12815020-7.00001-1

6. Basak, S., Dixit, U., et al. (2007). Application of radial basis function neural networks in optimization of hard turning of AISI D2 cold-worked tool steel with a ceramic tool. Proceedings of the Institution of Mechanical Engineers, Part B: Journal of Engineering Manufacture, vol. 221,987-998. DOl:10.1243/ $09544054 J E M 737$.

7. Ozcelik, B., Oktem, H., et al. (2005). Optimum surface roughness in end milling Inconel 718 by coupling neural network model and genetic algorithm. The International Journal of Advanced Manufacturing Technology, vol. 27,234-241. DOI:10.1007/ s00170-004-2175-7.

8. Do, T.V. and Nguyen, Q.M., et al. (2020). Optimization of Cutting Parameters for Improving Surface Roughness during Hard Milling of AISI H13 Steel. Key Engineering Materials, 831, 35-39.DOI:10.4028/ www.scientific.net/KEM.831.35 
9. Bai, X., Li, C., et al. (2019). Experimental evaluation of the lubrication performances of different nanofluids for minimum quantity lubrication (MQL) in milling Ti-6Al-4V. The International Journal of Advanced Manufacturing Technology, vol. 101,2621-2632. DOI:10.1007/s00170-018-3100-9.

10. Suarez, M.P., Marques, A., et al. (2019). MoS2 solid lubricant application in turning of AISI D6 hardened steel with PCBN tools. Journal of Manufacturing Processes, vol. 47,337-346. DOI:10.1016/j.jmapro.2019.10.001.

11. Patole, P. and Kulkarni, V. (2017). Experimental investigation and optimization of cutting parameters with multi response characteristics in MQL turning of AISI 4340 using nano fluid. Cogent Engineering, vol. 4,1303956. DOI:10.1080/23311916.2017.13039 56.

12. Bag, R., Panda, A., et al. (2020). A brief study on effects of nano cutting fluids in hard turning of AISI 4340 steel. Materials Today: Proceedings, DOI:10.1016/j. matpr.2020.02.640

13. Yıldırım, C.V., Sarıkaya, M., et al. (2019). The effect of addition of hBN nanoparticles to nanofluid-MQL on tool wear patterns, tool life, roughness and temperature in turning of Ni-based Inconel 625. Tribology International, vol. 134,443-456. DOI:10.1016/j. triboint.2019.02.027.

14. Sarhan, A.A., Sayuti, M., et al. (2012). Reduction of power and lubricant oil consumption in milling process using a new $\mathrm{SiO}_{2}$ nanolubrication system. The International Journal of Advanced Manufacturing Technology, vol. 63,505-512. DOI:10.1007/s00170012-3940-7.

15. Roy, S., Kumar, R., et al. (2019). A brief review on effects of conventional and nano particle based machining fluid on machining performance of minimum quantity lubrication machining. Materials Today: Proceedings, vol. 18,5421-5431. DOI:10.1016/j.matpr.2019.07.571.
16. Rosnan, R., Murad, M.N., et al. (2019). Effects of minimal quantity lubricants reinforced with nano-particles on the performance of carbide drills for drilling nickel-titanium alloys. Tribology International, vol. 136,58-66. DOI:10.1016/j.triboint.2019.03.029.

17. Osman, K.A., Yılmaz, V., et al. (2020). Slot milling of titanium alloy with hexagonal boron nitride and minimum quantity lubrication and multi-objective process optimization for energy efficiency. Journal of Cleaner Production, 120739. DOI:10.1016/j.jclepro.2020.120739.

18. Kumar, R., Sahoo, A.K., et al. (2020). Influence of $\mathrm{Al}_{2} \mathrm{O}_{3}$ and $\mathrm{TiO}_{2}$ nanofluid on hard turning performance. The International Journal of Advanced Manufacturing Technology, vol. 106,2265-2280. DOI:10.1007/s00170-019-04754-3.

19. Said, Z., Gupta, M., et al. (2019). A comprehensive review on minimum quantity lubrication (MQL) in machining processes using nano-cutting fluids. The International Journal of Advanced Manufacturing Technology, vol. 105,2057-2086. DOI:10.1007/ s00170-019-04382-x.

20. Nguyen, H.-T. and Hsu, Q.-C.(2016). Surface roughness analysis in the hard milling of JIS SKD61 alloy steel. Applied sciences, vol. 6,172. DOI:10.3390/ app6060172.

21. Hassanpour, H., Sadeghi, M.H., et al. (2016). Investigation of surface roughness, microhardness and white layer thickness in hard milling of AISI 4340 using minimum quantity lubrication. Journal of Cleaner Production, vol. 120,124-134. DOI:10.1016/j.jclepro.2015.12.091.

22. Khandekar, S., Sankar, M.R., et al. (2012). Nano-cutting fluid for enhancement of metal cutting performance. Materials and Manufacturing Processes, vol. 27,963-967. DOI:10.1080/10426914.2011.6100 78. 